Western University

Scholarship@Western

Family Medicine Publications

Family Medicine Department

2014

\title{
Attention Deficit Hyperactivity Disorder, other mental health problems, substance use and driving: Examination of a population-based, representative Canadian sample
}

Evelyn R. Vingilis

Western University, evingili@uwo.ca

Robert Mann

Centre for Addiction and Mental Health, Robert.Mann@camh.ca

Pat Erickson

University of Toronto, pat.erickson@utoronto.ca

Maggie Toplak

York University

Nathan Kolla

University of Toronto, nathan.kolla@utoronto.ca

See next page for additional authors

Follow this and additional works at: https://ir.lib.uwo.ca/fammedpub

Part of the Medicine and Health Sciences Commons

Citation of this paper:

Cite as: Vingilis, E., Mann, R. E. Erickson, P. Toplak, M., Kolla, N. J., and Seeley, J. (2014) Attention Deficit Hyperactivity Disorder, other mental health problems, substance use and driving: Examination of a population-based, representative Canadian sample. Traffic Injury Prevention, 15:sup1, S1-S9, DOI:10.1080/15389588.2014.926341. 
Authors

Evelyn R. Vingilis, Robert Mann, Pat Erickson, Maggie Toplak, Nathan Kolla, Jane Seeley, and Umesh Jain 
Attention Deficit Hyperactivity Disorder, other mental health problems, substance use and driving: Examination of a population-based, representative Canadian sample

Evelyn Vingilis, PhD, C. Psych. Population and Community Health Unit, Department of Family Medicine Department of Family Medicine, University of Western Ontario, 1151 Richmond St. London, ON, Canada N6A 5C1, email: evingili@uwo.ca

Robert E. Mann, PhD, Centre for Addiction and Mental Health; Dalla Lana School of Public Health, University of Toronto

Patricia Erickson, PhD, Department of Sociology; Centre for Criminology and Sociological Studies, University of Toronto

Maggie Toplak, PhD, C. Psych, Department of Psychology, York University; LaMarsh Centre for Child and Youth Research

Nathan J. Kolla, MD, MSc, Centre for Addiction and Mental Health; Department of Psychiatry, University of Toronto; Centre for Addiction and Mental Health, Complex Mental Illness, Forensic Service

Jane Seeley, BA, Population and Community Health Unit, Department of Family Medicine, University of Western Ontario

Umesh Jain, MD, PhD, Consultant Psychiatrist Hospital for Sick Children, Toronto

Cite as: Vingilis, E., Mann, R. E. Erickson, P. Toplak, M., Kolla, N. J., and Seeley, J. (2014) Attention Deficit Hyperactivity Disorder, other mental health problems, substance use and driving: Examination of a population-based, representative Canadian sample. Traffic Injury Prevention, 15:sup1, S1-S9, DOI:10.1080/15389588.2014.926341. 


\section{Abstract}

Purpose: The purpose of this study is to examine the relationships among self-reported screening measures of ADHD, other psychiatric problems, and driving-related outcomes in a provincially representative sample of adults 18 years and older living in the province of Ontario, Canada. Methods: The study examined the results of the Centre for Addictions and Mental Health (CAMH) Ontario Monitor, an ongoing repeated cross-sectional telephone survey of Ontario adults over a two year period. Measures: ADHD measures (Adult ADHD Self-Report Scale-V1.1 (ASRS-V1.1), previous ADHD diagnosis, ADHD medication use); psychiatric distress measures (General Health Questionnaire (GHQ12), pain, anxiety and depression medication use); antisocial behaviour measure (The Antisocial Personality Disorder Scale from the MiniInternational Neuropsychiatric Interview (APD)); substance use and abuse measures (alcohol, cannabis and cocaine), Alcohol Use Disorders Identification Test (AUDIT), Alcohol, Smoking and Substance Involvement Screening Test (ASSIST)); driving-related outcomes (driving after drinking, driving after cannabis use, street racing, collisions in past year) and sociodemographics (gender, age, vehicle km travelled).

Results: A total of 4014 Ontario residents were sampled, of which 3485 reported having a valid driver's licence. Overall, 3.22\% screened positively for ADHD symptoms on the ASRS-V1.1 screening tool. A greater percent of those who screened positively were younger, reported previous ADHD diagnosis and medication use, distress, antisocial behaviour, anti-anxiety and anti-depressant medication use, substance use and social problems compared to those who screened negatively. However, there were no statistically significant differences between those 
who screened positively or negatively for ADHD symptoms on self-reported driving after having two or more drinks in the previous hour, within an hour of using cannabis, marijuana or hash, in a street race or collision involvement as a driver in the past year. When a sequential regression was conducted to predict self-reported collisions, younger age, higher weekly kilometres driven showed higher odds of collision involvement, while the odds ratio for cannabis use ever, approached statistical significance.

Discussion: This study is the first population-based study of a representative sample of adults 18 years and older living in Ontario, Canada. These results showed no relationship between the ADHD screen and collision when age, sex and kilometres driven are controlled for. However, these analyses are based on self-report screeners and not psychiatric diagnoses and a limited sample of ADHD respondents. Thus, these results should be interpreted with caution. 


\section{Introduction}

Attention Deficit Hyperactivity Disorder (ADHD) is a complex neurodevelopmental disorder. According to the Diagnostic and Statistical Manual of Mental Disorders, $5^{\text {th }}$ edition, (DSM-5), ADHD includes symptoms of inattention, hyperactivity and impulsivity with clear evidence of impairment in multiple domains and onset of symptoms by age twelve (American Psychiatric Association 2013). Historically, ADHD was viewed as a diagnosis for children and adolescents as it was believed to diminish before adulthood (Goodman 2007). However, followup studies during the last 30 years have added ADHD to the range of adult psychiatric conditions, although evidence suggests that the number and severity of symptoms decline with age (Cuffe et al. 2005; Faraone et al. 2005). Diagnosis of ADHD is further complicated by the higher presence of comorbidities, such as mood, anxiety, conduct (CD), oppositional defiant (ODD), anti-social personality and substance use disorders in persons with diagnosed ADHD when compared to normal controls (Asherson et al. 2007; Kessler et al. 2006; Secnik et al. 2005; Weiss et al. 1985; Young et al. 2003). Indeed, Brassett-Harknett and Butler (2007) write: "Current expert opinion is that it is uncommon to find 'pure' AD/HD." (p.195)

Correlational and experimental studies have been conducted to assess whether adolescents and adults with ADHD have a higher propensity to risky driving, commit driving offences and be involved in collisions (Barkley et al. 1993, 2002; Fried et al. 2006; Murphy and Barkley, 1996; Nada-Raja et al. 1997; Woodward et al. 2000). However, most studies exhibit serious methodological problems, such as referral bias, self-reporting, inappropriate or nondefined comparison groups, non-blinded research staff, participant attrition, lack of adjustment for multiple comparisons, small sample sizes, lack of statistical controls for age, sex and driving exposure, and lack of controls for ADHD medication use and comorbidities. 
Observational studies conducted primarily with clinical samples have often shown higher rates of driving violations and collisions for persons with ADHD compared to control groups, with relative risks for collisions ranging from 0.42 to 18.3 (Vaa 2014). A recent meta-analysis found a relative collision risk for drivers with ADHD decreased significantly from 1.36 to 1.23 when correcting for publication bias and controlling for driving exposure. This risk could be even lower because ADHD drivers seem to drive more than controls, and the majority of studies in the meta-analysis lacked information on driving exposure (Vaa 2014). The relative collision risk was 1.86 in a sample of ADHD drivers in which the majority had comorbid conduct disorder, oppositional defiant disorder and/or other conduct problems, suggesting that these comorbidities may increase collision risk (Vaa 2014). The meta-analysis also clarified that although ADHD drivers had more speeding violations, they did not have more drinking-driving or reckless driving violations (Vaa 2014).

The possibility that comorbid conditions in ADHD may account for negative driving outcomes is important for informing intervention and treatment choices. Some studies have found no relationships between an ADHD diagnosis and negative driving outcomes (Secnik et al. 2005). Other studies have found that comorbid externalizing disorders, such as conduct, oppositional defiant or antisocial personality disorders, partially or fully explained negative driving-related outcomes (Barkley et al. 1993; Barkley and Cox 2007; Fried et al. 2006; Thompson et al. 2007; Woodward et al. 2000). In an early, well-cited study of ADHD and negative driving outcomes, Barkley et al. (1993) wrote: “All of the negative driving-related outcomes as well as driving skill deficiencies are significantly related to the degree of antisocial symptoms (ODD/CD) shown by these subjects. The degree of ADHD symptoms seems to make an additional unique contribution only to the number of times a subject had illegally driven 
without a driver's license". (p. 217) However, the authors then concluded: "An almost fourfold increase in the average frequency of being involved in motor vehicle crashes as drivers was noted for subjects with ADHD relative to control subjects" (Barkley et al. 1993. pp.217-218). Yet other studies found no effects of comorbidities on the positive relationship between ADHD and negative driving outcomes. Barkley et al. (2002) found a relationship between ADHD and traffic citations, collisions and licence suspensions, but failed to replicate the associations they previously found between oppositional defiant disorder and driving-related outcomes.

Internalizing disorders are also commonly comorbid with ADHD in adolescents and adults (Biederman et al. 2006; Fayyad et al. 2007; Secnik et al. 2005). Internalizing disorders have been associated with negative driving outcomes including increased collision and injury risk in general population samples (Mann et al. 2010; Vingilis and Wilk 2008). However, limited research is available on internalizing disorders, ADHD and negative driving outcomes and show contradictory findings (Barkley et al. 2002; Fried et al. 2006).

Studies of adults with ADHD have also found higher rates of alcohol and drug use and problems when compared with control samples (Brassett-Harknett and Butler 2007; Goodman 2007; Kessler et al. 2006; Secnik et al. 2005; Wolraich et al. 2005; Young et al. 2003). However, the limited studies that examined drinking driving behaviours of ADHD adults have found mixed results. Studies have found that clinical ADHD and community control groups did not differ in the proportion that self-reported drinking driving or drinking driving collisions (Barkley et al. 1993, 1996; 2002; Thompson et al. 2007), although those with conduct problems did report more impaired driving (Thompson et al. 2007). Yet longitudinal studies found that those with attentional difficulties or ADHD were significantly more likely to report driving after drinking, driving while seriously intoxicated, and to be arrested for drinking driving (Nada-Raja 
et al. 1997; Woodward et al. 2000). However, no studies have examined cannabis or cocaine use and driving in relation to ADHD.

Research has generally found evidence of improved driving among adolescent and adult drivers with ADHD medication use (Cox et al. 2000, 2006; Hechtman et al. 1984; Sobanski et al. 2008; Wolraich et al. 2005). One follow-up study of adults who had been diagnosed with ADHD as children found that those who had received medication in childhood for their ADHD reported fewer collisions as adults compared to those who went untreated or to non-ADHD controls. However, self-reports of the cost of the collisions, extent of bodily injury and use of alcohol, drugs or emotional states at time of the collision did not differ among groups (Hechtman et al. 1984). Some experimental, laboratory simulator studies have found better simulator driving performance in persons using ADHD medications compared to placebo control groups (Cox et al. 2000, 2004, 2006). However, other research has shown poor concordance between laboratoryor clinic-based measures of response to ADHD medication and actual performance (Thompson et al. 2007). A simulator study found differences in only 3 of 18 measures between the ADHD placebo condition and the low or high doses of methylphenidate conditions (Barkley et al. 2005). Nevertheless, the authors conclude: "the results, when placed in the context of prior studies of stimulants on driving performance, continue to recommend their clinical use as one means of reducing the driving risks in ADHD teens and adults" (Barkley et al. 2005, p. 121).

One important methodological challenge is the use of clinical samples. Clinical samples are derived through a series of filters which introduce a series of biases. ADHD samples are generally drawn from various treatment facilities. However, only a small proportion of those with ADHD symptoms are diagnosed and/or seek treatment through clinics and hospital units (Cuffe et al. 2005). For example, prevalence differences for ADHD in boys and girls vary by 
sampling methods, with clinically-referred studies having gender differences close to 9:1, while epidemiological studies have gender differences closer to 3:1 (Gerson 2002). Some suggest that girls with ADHD display less disruptive behaviours, which lead to fewer referrals than the attention-getting conduct of boys (Chen and Taylor 2005; Gerson 2002). Clinical samples have the advantage of extensive assessment but the disadvantage of a lack of representativeness of those with ADHD symptoms (Cunningham and Boyle 2002; Rowland et al. 2002). Clinical samples also seem to show more symptoms, impairment, comorbidities and other differences compared to community samples (Rowland et al. 2002). For example, Young et al. (2003) found fewer life history, social functioning and comorbidity differences between an ADHD clinical group drawn from an adult ADHD assessment clinic that met the diagnostic criteria for ADHD and a clinical control group that did not meet ADHD criteria, than between the ADHD group and a non-clinical control group. Population-based samples can be used for making inferences to the general population (Cunningham and Boyle, 2002; Rowland et al. 2002). Thus, a populationbased study can contribute to our understanding of ADHD, risky driving and covariates, although it is important to point out that large, population-based surveys must rely on screening instruments and thus are limited by the measurements.

The purpose of this study is to examine the relationships among self-reported screening measures of ADHD, other psychiatric problems, and driving-related outcomes in a provincially representative sample of adults living in the province of Ontario, Canada.

\section{Methodology}

The data are based on telephone interviews with 4,014 respondents over 24 months between January, 2011 and December 2012. These data were collected through the Centre for Addiction and Mental Health (CAMH) Monitor, an ongoing cross-sectional, computer assisted telephone 
survey (landlines and cell phones) of Ontario adults (ages 18 or older) using a stratified twostage probability selection procedure occurring each quarter. The survey is conducted by CAMH and administered by the Institute for Social Research at York University (see Ialomiteanu and Adlaf 2012 for details). Each monthly cycle uses a two-stage probability sampling procedure. In the first stage, a random sample of telephone numbers was selected with equal probability from within each regional stratum. In the second stage, one respondent aged 18 or older who was able to complete the interview in English was then selected from within each household according to the most recent birthday of all household members. Response rates based on estimated eligible sample averaged $52.89 \%$. The study received ethical approval from the CAMH, York University and the University of Western Ontario research ethics boards.

\section{Measures}

ADHD measures

- The Adult ADHD Self-Report Scale-V1.1 (ASRS-V1.1) was developed by Kessler et al. (2005) in conjunction with revision of the WHO Composite Diagnostic Interview. The screener consists of 6-items, each with 5-point Likert scale response options, found to be most predictive of a DSM IV-based diagnosis of ADHD (Able et al. 2007; Adler et al. 2006; Kessler et al. 2005, 2007). A positive ADHD symptoms screen is a total score greater than 13 (Kessler et al. 2007).

- Previous ADHD diagnosis was assessed by the item 'have you ever been diagnosed with Attention Deficit Disorder (ADD) or Attention Deficit Hyperactivity Disorder (ADHD) by a doctor or health care professional?' Youth endorsing an ADHD diagnosis also concurrently reported significantly more DSM-IV symptoms of ADHD than youth not endorsing a diagnosis of ADHD (Langhinrichsen-Rohling et al. 2005). 
- ADHD Medication use was assessed by items querying participants if and when they had ever been treated with medication for ADHD or ADD by a doctor or health care professional?' (adapted from Ontario Student Drug Use and Health Survey, Paglia-Boak et al. 2012).

Psychiatric distress (anxiety/depression) measures and medication use

- The General Health Questionnaire (GHQ12) is a widely used 12-item screening instrument, with good psychometric properties, for current psychiatric distress. It captures depression/anxiety and problems with social functioning (Donath 2001; Goldberg and Hillier 1979; Hardy et al. 1999). A score of three and higher is a positive screen;

- Pain/anxiety/depression medication use: In the past 12 months have you taken any prescription medication: for pain? to reduce anxiety or panic attacks? to reduce depression?

Antisocial behaviour measure:

- Antisocial Personality Disorder Scale from the Mini-International Neuropsychiatric Interview (MINI-APD), a 12-item, dichotomous scale, was designed to provide a short clinical screening tool to assess whether the following sets of delinquencies (truancy, cheating/lying/stealing, bullying, hurting animals/people) were committed before age 15 and after age 15 (Sheehan et al., 1998). We excluded one item of the MINI-APD (forced someone to have sex before age 15), as required by the ethics review board. A score of three or more on the latter six MINI-APD questions indicated a positive APD screen.

Substance use and abuse measures:

- $\quad$ Lifetime cannabis and cocaine use; 
- $\quad$ Binge drinking ( five or more drinks at the same sitting or occasion at least once in the past 12 months);

- $\quad$ Alcohol Use Disorders Identification Test (AUDIT) is a 10-item, validated screening instrument developed by the WHO, to detect individuals at the less severe end of the spectrum of alcohol problems, with a score eight and greater indicating hazardous alcohol use (Newcombe et al. 2005; Saunders et al. 1993; WHO ASSIST Working Group 2002).

- The cannabis subscale of the Alcohol, Smoking and Substance Involvement Screening Test (ASSIST) is a 6-item screening instrument to assess, for users of cannabis, the risk of experiencing health and other problems (e.g., social, financial, legal, relationship) from their current pattern of use, with score four and greater indicating moderate or high risk of problems (WHO ASSIST Working Group, 2002).

\section{Driving-related problem behaviours:}

- Drinking/driving: (“...have you driven a motor vehicle after having two or more drinks in the previous hour?”); cannabis use/driving: (“...have you driven a motor vehicle within an hour of using cannabis, marijuana or hash?"; street racing: (..."how many times, if at all, have you driven a car, truck or SUV in a street race?") and collision involvement: ("how often, if at all, were you involved in an accident or collision involving any kind of damage to you or another person or vehicle while you were driving...”, were each assessed according to whether or not respondents reported one or more instances "during the past 12 months".

Socio-demographics:

- $\operatorname{Sex}($ male $=0$, female $=1)$; age; kilometres driven per week.

\section{Statistical Analysis}


IBM SPSS Statistics 20 (IBM SPSS Statistics, 2011) software was used in all analyses. The results in this paper are based on "valid" responses (n's) such that missing data (i.e. "don't know" responses and refusals) were excluded from analyses. The percentages reported are based on the weighted sample size and are considered representative for the population surveyed (Ialomiteanu and Adlaf, 2004). Bivariate analyses ( $X^{2} \mathrm{~s}$ and t-tests) were used to compare differences between respondents who screened positively and negatively for ADHD symptoms and for those who reported at least one collision versus none in the past year. The results are interpreted using a Bonferroni correction of .0028 for 18 comparisons. A sequential logistic regression was performed considering self-reported collisions as the dependent variable. Age (18-24, 25-44,45$64, \geq 65$ ), sex and driving exposure as control variables were entered in the first block, ADHD screening status in the second block, antisocial behaviour screener and distress in the third block and substance use/abuse variables of the ASSIST, cannabis and cocaine use in the fourth block. Sequential logistic regression is a commonly used procedure that allows the researcher to assign order of entry of variables based on logical or theoretical considerations and to determine whether prediction of the dependent variable improves with the additional independent variables added to the equation (Tabachnik and Fidell, 2007). The ordering of variables for the sequential logistic regression reflected the conceptualization and findings of the ADHD and comorbidity literature with ADHD, as a neurodevelopmental disorder occurring prior to psychiatric distress and antisocial behaviours, which could affect substance use and abuse (Acherson et al. 2007; Goodman 2007; Hechtman et al. 1984; Secnik et al. 2005; Weiss et al. 1985; Wolraich et al. 2005; Young et al. 2003).

\section{Results}


Overall, 3.22\% of the sample of self-reported licensed drivers screened above the cut-off for positive ADHD symptoms. Table 1 shows significant differences between those who screened positively and negatively for ADHD symptoms. A greater percent of those who screened positively were younger, reported previous ADHD diagnosis and medication use, distress, antisocial behaviour, anti-anxiety and anti-depressant medication use, substance use and social problems compared to those who screened negatively. However, there were no statistically significant differences between those who screened positively or negatively for ADHD symptoms on self-reported drinking driving cannabis use and driving or in a street race. Also no between group differences were found for collision involvement as a driver in the past year.

Few significant differences were found for respondents who reported a collision in the last 12 months compared to those who reported no collisions (Table 2). Only age, lifetime cannabis use, the ASSIST, and racing were significantly associated with self-reported collision involvement in the past year.

Table 3 provides the results of the sequential logistic regression. In block 1 the control variables of age, sex and driving exposure provided statistically significant improvement over the constant only model $\left(X^{2}=26.458, d f=5, p<.000\right)$. The odds ratio for age over 65 showed statistical significance, indicating a lower odds of respondents over 65 years of age reporting at least one collision compared to the 16-24 year old group (OR=.382, CI .185, .789). The odds ratio for driving exposure was also statistically significant $(\mathrm{OR}=1.000$, CI 1.000, 1.001). In block 2, the entry of ADHD screener status did not statistically significantly improve the model (block $X^{2}=.130, d f=1, p=.718$ ) over and above that accounted for by the control variables. When antisocial behaviour and the distress measures were added in block 3 , the model showed no improvement (block $X^{2}=2.097, d f=2, p=.350$ ). In block 4, the entry of the substance use and 
problems measures (ASSIST, use of cannabis in lifetime and use of cocaine in lifetime) showed a statistically significant model improvement (block $X^{2}=9.521, d f=3, p=.023$ ). Although no individual variables showed statistically significant odds ratios, use of cannabis ever neared statistical significance $(\mathrm{OR}=1.404, \mathrm{CI} .992,1.988, p=.056)$. The final model correctly classified $99.1 \%$ of no collision status, $2.2 \%$ of collision status and $93.5 \%$ of all cases overall at a cut-off value of .150 .

\section{Discussion}

This study is the first Canadian population-based assessment of ADHD symptoms and driving outcomes. Our ADHD symptom prevalence of $3.1 \%$ is congruent with the average ADHD prevalence of $3.4 \%$ found in a review of international studies of ADHD prevalence using similar sampling methodology (Fayyad et al. 2007). Consistent with other studies, the results show that a greater percentage of those who screened positively for ADHD symptoms compared to those who screened negatively for ADHD symptoms reported higher rates of psychiatric problems (distress, antisocial behaviours and substance use and problems). Additionally, a greater percentage of those who screened positively for ADHD symptoms compared to those who screened negatively for ADHD symptoms reported taking anti-anxiety and anti-depressant medications in the past year. However, no statistically significant differences were found between those who screened positively and negatively for ADHD symptoms and self-reported driving behaviours and outcomes, namely driving after having two or more drinks in the previous hour, within an hour of using cannabis, marijuana or hash, in a street race or collision involvement as driver in past year.

Examination of collision status identified cannabis use and problems and racing as variables associated with collisions but not ADHD positive symptoms, ADHD diagnosis or 
ADHD medication use, although the small cell sizes prevent definitive statements regarding this lack of positive results. A significantly greater percentage of persons who reported ever using cannabis and who scored in the moderate/high problems for cannabis use reported a collision in the past year. Studies on the relationship between cannabis use and negative driving outcomes have generally shown a positive relationship, particularly for acute cannabis consumption, although a number of studies and reviews have also found no relationship (Asbridge et al. 2012; Elvik 2013; Li et al. 2012; Mann et al. 2007; Ramaekers et al. 2004; Vingilis and Macdonald 2002). In the current study, no relationship was found between self-reported driving within an hour of using cannabis and collisions, suggesting that the relationship found between ever used cannabis, the ASSIST and collisions may be due to factors other than driving impairment. The sequential logistic regression indicated that when age and driving exposure were controlled, cannabis use was no longer associated with higher odds of self-reported collisions, although the association did approach statistical significance.

These data provide a valuable perspective on the relationship between ADHD symptoms and collision involvement in a large, population-based sample. Previous studies have indicated that individuals with ADHD are at substantially greater risk of collision involvement (e.g., Barkley et al. 1993). However, these studies were typically based on clinical samples that may be subject to substantial forms of bias, as well as failing to control for comorbidities and important confounders such as driving exposure. Other studies found the relationship between ADHD status and negative driving outcomes mediated by other comorbidities (Barkley et al. 1993; Barkley and Cox 2007; Fried et al. 2006; Thompson et al. 2007; Woodward et al. 2000) and yet other studies found no relationship between ADHD status and negative driving outcomes (Secnik et al. 2005). A recent meta-analysis suggested that evidence for an association of 
ADHD with driving risks decreased as potential confounders were controlled (Vaa 2014). In our study, we were able to control for demographic and driving exposure measures and comorbidities including psychiatric distress and substance use and problems. When we did so, we found no evidence for a significant association of ADHD symptoms with collision risk in this sample.

Our results are thus in substantial agreement with the results of the recent meta-analysis by Vaa (2014) in suggesting that the strong association of ADHD with collision risk seen in some earlier studies may have been an artefact of the study designs used and a failure to control for potential confounders. Studies of clinical samples are subject to referral bias, and among individuals with ADHD other comorbid conditions, many of which are also associated with increased collision risk, are often observed, as shown in Table 1. Thus, findings in previous studies suggesting that ADHD is associated with substantively increased collision risk may have instead been reflecting the impact of design bias and comorbid factors.

This does not mean that there is no need to be concerned about collision risk among those experiencing ADHD. Instead, it suggests the need for more complex broad-based research as ADHD is a complex disorder with heterogeneity in neuropsychological pathways, comorbidities and symptom presentations (Coghill et al. 2005; Nigg et al. 2005; Toplak et al. 2008; Wåhlstedt et al. 2009). Driving and collision risk research among those with ADHD also needs to include road safety researchers so that collision risk may better be assessed by including validated methods and measures and other factors known to increase risk, such as drug use.

The results of this study are subject to important limitations. These data are based on self-report screeners and do not reflect the breadth of information needed for clinical diagnoses. This is a key issue because the current study only reflects self-reported symptoms and does not 
examine impaired functioning and other issues related to specific diagnoses. Thus, this population based sample may represent functioning persons with some ADHD and/or other comorbid symptoms but not actual diagnoses and as such, the study findings may be biased toward persons with fewer negative driving outcomes. It is not possible to assess sampling bias as no information on non-respondents was available. Thus it is unknown whether those with ADHD were more or less likely to participate in the survey, although the age trends and relationships found in Table 1 between ADHD symptoms and more comorbidities and other difficulties, are consistent with many other studies (e.g. Able et al.2007; Brassett-Harknett and Butler 2007; Cuffe et al. 2005; Faraone et al. 2005) and serve to validate the ADHD self-report construct in a community sample.

Other variables, such as collisions, drinking driving, etc. are also based on self-reports and can be subject to memory problems and social desirability, although in our study $6.1 \%$ reported a collision while official statistics indicate about $4 \%$ of licensed drivers yearly are reported to police to be involved in a collision in Ontario (Ministry of Transport of Ontario, 2014), suggesting that underreporting among survey respondents did not occur. Other Canadian research examining whether self-reported collision injury rates in a national population survey using equivalent sampling methods to our survey were a valid measure of police-reported, official collision injury rates in Canada, found no significant differences in rates when the two datasets were compared for the gender and age categories or for trends over time (Roberts et al. 2008), indicating that that self-reports for collisions may be reasonably accurate. Additionally, although the response rate over 50\% is good for a telephone survey and data were weighted, the sample could potentially be biased. Finally, although the total sample size is over 4000, cell sizes can be very small because psychiatric problems, such as ADHD, substance use and 
collisions have low prevalence; small cell sizes and large CIs suggest a low level of precision, as indicated in some of the variables in Table 3.

Despite these limitations, these observations are of substantial interest. Additional research to confirm that the impact of ADHD symptoms on collision risk is more modest or more complex than suggested in previous studies is needed to ensure an appropriate response to potential traffic safety concerns associated with this condition.

\section{Acknowledgements}

This study was supported by a Canadian Institutes for Health Research operating grant (\#MOP 102537). 


\section{References}

Able SL, Johnston JA, Adler LA, Swindle RW. Functional and psychosocial impairment in adults with undiagnosed ADHD. Psychol Med. 2007;37:97-107.

Adler LA, Spencer T, Faraone SV, et al. Validity of pilot adult ADHD self-report scale (ASRS) to rate adult ADHD symptoms. Ann Clin Psychol. 2006;18(3):145-8.

American Psychiatric Association. Desk Reference to the Diagnostic Criteria from DSM-5. Arlington, VA: American Psychiatric Association; 2013.

Asbridge M, Hayden JA, Cartwright JL. Acute cannabis consumption and motor vehicle collision risk: systematic review of observational studies and meta-analysis. $\mathrm{Br} \mathrm{Med} J$. 2012;344:e536-545.

Asherson P, Chen W, Craddock B, Taylor E. Adult attention-deficit hyperactivity disorder: recognition and treatment in general adult psychiatry. Br J Psychiat. 2007;190:4-5.

Barkley RA, Cox D. A review of driving risks and impairment associated with attentiondeficit/hyperactivity disorder and the effects of stimulant medication on driving performance. $J$ Safety Res. 2007;38:113-128.

Barkley RA, Guevremont DC, Anastopoulos AD, DuPaul GJ, Shelton TL. Driving-related risks and outcomes of attention deficit hyperactivity disorders in adolescents and young adults: a 3 to 5 year follow-up survey. Pediatrics. 1993;92:212-218.

Barkley RA, Murphy KR Kwasnik D. Motor vehicle driving competencies and risks in teens and young adults with attention deficit hyperactivity disorder. Pediatrics. 1996;98:1089-1095.

Barkley RA, Murphy KR, DuPaul GJ, Bush T. Driving in young adults with attention deficit hyperactivity disorder: knowledge, performance, adverse outcomes, and the role of executive functioning. J Int Neuropsychol Soc. 2002;8:655-672.

Barkley RA, Murphy KR, O'Connell T, Connor D. Effects of two doses of methylphenidate on simulator driving performance in adults with attention deficit hyperactivity disorder. $J$ Safety Res. 2005;36:121-131.

Barkley RA, Murphy KR, O'Connell T, Anderson D, Connor DF. Effects of two doses of alcohol on simulator driving performance in adults with attention-deficit/hyperactivity disorder. Neuropsychol. 2006;20:77-87.

Biederman J, Faraone SV, Monuteaux MC, et al. Gender effects of attention deficit hyperactivity disoerder in adults, revisited. Biolog Psychiatry. 2004:55;692-700.

Biederman J, Monuteaux MC, Mick E, et al. Young adult outcome of attention deficit hyperactivity disorder: a controlled 10-year follow-up study. Psychol Med 2006;36:167-79. 
Brassett-Harknett A, Butler N. Attention-deficit/hyperactivity disorder: An overview of the etiology and a review of the literature relating to the correlates and lifecourse outcomes for men and women. Clin Psychol Rev. 2007;27:188-210.

Chen W, Taylor E. Resilience and self-control impairment. In: Goldstein S, Brooks RB, Eds. Handbook of Resilience in Children 7th ed. New York: Springer;2005;257-278.

Coghill D, Nigg J, Rothenberger A, Sonuga-Barke E, Tannock R. Whither causal models in the neuroscience of ADHD? Devel Sci. 2005;8:105-114.

Cox D, Merkel R, Kovatchev B, Seward R. Effect of stimulant medication on driving performance of young adults with attention-deficit hyperactivity disorder: a preliminary doubleblind placebo controlled trial. J Nerv Ment Dis 2000;188:230-234.

Cox D, Merkel R, Moore M, Thorndike F, Muller C, Kovatchev B. Relative benefits of stimulant therapy with OROS methylphenidate versus mixed amphetamine salts extended release in improving the driving performance of adolescent drivers with attention-deficit/hyperactivity disorder. Pediatrics 2006;118:E704-E710.

Cuffe SP, Moore CG, McKeown RE. Prevalence and correlated of ADHD symptoms in the National Health Interview Survey. J Atten Disord. 2005;9:392-401.

Cunningham CE, Boyle MH. Preschoolers at risk for attention-deficit hyperactivity disorder and oppositional defiant disorder: family, parenting, and behavioral correlates. J Abnorm Child Psychol. 2002;30:555-69.

Donath S. The validity of the 12-item General Health Questionnaire in Australia: a comparison between three scoring methods. Austral N Z J Psych 2001;35:231-5.

Elvik R. Risk of raod accident associated with the use of drugs: A systematic review and metaanalysis of evidence from epidemiological studies. Acc Anal Prev. 2013;60:254-267.

Faraone SV, Biederman J, Mick E. The age dependent decline of attention deficit hyperactivity disorder: a meta-analysis of follow-up studies. Psychol Med. 2005;35:1-7.

Fayyad J, De Graaf R, Kessler R, et al. Cross-national prevalence and correlates of adult attention-deficit hyperactivity disorder. Brit J Psychiatry 2007;190:402-9.

Fischer M, Barkley RA, Smallish L, Fletcher K. Hyperactive children as young adults: driving abilities, safe driving behavior, and adverse driving out-comes. Accid Anal Prev. 2007;39:94105.

Fried R, Petty C, Surman C, Reimer B, et al. Characterizing impaired driving in adults with attention deficit/hyperactivity disorder: a controlled study. J Clin Psychiat. 2006;67:567-574. 
Gershon J. A meta-analytic review of gender differences in ADHD. J Atten Disord. 2002;5(3):143-54.

Goldberg DP, Hillier VF. A scaled version of the General Health Questionnaire. Psychol Med. 1979;9:139-45.

Goodman DW, The consequences of Attention-Deficit/Hyeractivity Disorder in adults. $J$ Psychiat Practice. 2007;13:318-327.

Hardy GE, Shapiro DA, Haynes CE, Rick JE. Validation of the General Health Questionnaire-12 using a sample of employees from England's health care services. Psychol Assess. 1999;11:15965 .

Hechtman L, Weiss G, Perlman T. Young adult outcome of hyperactive children who received long-term stimulant treatment. J Am Acad Child Adolesc Psychiatry. 1984;23:261-269.

Kessler RC, Adler L, Ames M, et al. The World Health Organization Adult ADHD Self-Report Scale (ASRS): a short screening scale for use in the general population. Psychol Med 2005;35:245-56.

Kessler RC, Adler L, Barkley RA, et al. The prevalence and correlates of adult ADHD in the United States: results from the National Comorbidity Survey Replication. Am J Psychiatry 2006; 163:716-723.

Kessler RC, Adler LA, Gruber MJ, Sarawate CA, Spender T, Van Brunt DL. Validity of the World Health Organization Adult ADHD Self-Report Scale (ASRS). Screener in a representative sample of health plan members. Int J Methods Psychol Res 2007;16(2):52-65.

Ialomiteanu A, Adlaf EM. CAMH Monitor 2011: metadata user's guide. Toronto, ON: Centre for Addiction and Mental Health; 2012. [cited 2014 Feb 25] Available from: http://www.camh.net/Research/camh_monitor.html

Langhinrichsen-Rohli J, Rebholz C, O-Brien N, O'Farrill-Swails L, Ford W. Self-reported co morbidity of depression, ADHD, and alcohol/substance use disorders in male youth offender residing in an alternative sentencing program. J Evidence-based Social Work. 2005;2:1-17.

Li MC, Brady JE, DiMaggio CJ, Lusardi AR, Tzong KY, Li G. Marijuana use and motor vehicle crashes. Epi Rev. 2012;34:65-72.

Mann RE, Adlaf E, Zhao J, et al. Cannabis use and self-reported collisions in a representative sample of adult drivers. J Safety Res. 2007;38:669-674.

Mann RE, Asbridge M, Stoduto G, et al. Psychological distress and collision involvement among adult drivers. Stress Health. 2010;26:127-134. 
Ministry of Transportation of Ontario. Ontario Road Safety Annual Report 2010. http://www.mto.gov.on.ca/english/safety/orsar/orsar10/ORSAR10.pdf

Nada-Raja S, Langley JD, McGee R, Williams SM, Begg DJ, Reeder AI. Inattentive and hyperactive behaviors and driving offenses in adolescence. J Am Acad Child Adolesc Psychiatry. 1997;36:515-522.

Newcombe DAL, Humeniuk RE, Ali R. Validation of the World Health Organization Alcohol, Smoking and Substance Involvement Screening Test (ASSIST): report of results from the Australian site. Drug Alcohol Rev. 2005;24(3):217-26.

Nigg Jt, Willcutt EG, Doyle AE, Sonuga-Barke EJS. Causal heterogeneity in attentiondeficit/hyperactivity disorder: Do we need neuropsychologically impaired substypes? Biol Psychiatry. 2005;57:1224-1230.

Paglia-Boak A, Mann RE, Adlaf EM, Hamilton HA, Beitchman JH, Wolfe D, et al. Detailed OSDUHS findings. The mental health and well-being of Ontario students 1991-2011. (CAMH Research Document Series No. 33). Toronto, ON: Centre for Addiction and Mental Health; 2012.

Reimer B, D'Ambrosio LA, Coughlin JE, Fried R, Biederman J. Task-induced fatigue and collisions in adult drivers with attention deficit hyper-activity disorder. Traffic Inj Prev. 2007;8:290-299.

Reimer B, Mehler B, D'Ambrosio LA, Fried R. The impact of distractions on young adults drivers with attention deficit hyperactivity disorder (ADHD). Accid Anal Prev. 2010;42:842-851

Roberts SE, Vingilis E, Wilk P, Seeley J. A comparison of self-reported motor vehicle collision injuries compared with official collision data: An analysis of age and sex trends using the Canadian National Population Health Survey and Transport Canada data. Accid Anal Prev. 2008;40:559-566.

Rowland AS, Lesesne CA, Abramowitz AJ. The epidemiology of attention-deficit/hyperactivity disorder (ADHD): a public health view. Ment Retard Dev Disabil Res Rev. 2002;8:162-70.

Saunders JB, Asland OG, Babor TF, De La Fuente JR, Grant M. Development of the Alcohol Use Disorders Identification Test (AUDIT): WHO Collaborative Project on early detection of persons with harmful alcohol consumption--II. Addiction. 1993;88(6):791-804.

Secnik K, Swensen A, Lage MJ. Comorbidities and costs of adult patients diagnosed with attention-deficit hyperactivity disorder. Pharmacoecon. 2005;23:93-102.

Sheehan DV, Lecrubier Y, Shehhan KH, et al. The Mini-International Interview (M.I.N.I.): the development and validation of a structured diagnostic interview for DSM-IV and ICD-10. J Clin Psychiatry 1998;59 Suppl 20:22-33. 
Smart RG, Mann RE. Is road rage a serious traffic problem? Traffic Inj Prev. 2002;3:183-189.

Sobanski E, Sabljic D, Alm B, et al. Driving-related risks and impact of methylphenidate treatment on driving in adults with attention-deficit/hyperactivity disorder (ADHD). J Neural Transm. 2008;115:347-356

Thompson AL, Molina BS, Pelham Jr W, Gnagy EM. Risky driving in adolescents and young adults with childhood ADHD. J Pediatric Psychol. 2007;32:745-759.

Toplak ME, Connors L, Shuster J, Knezevic B, Parks S. Review of cognitive, cognitivebehavioral and neural-based interventions for Attention-Deficit/Hyperactivity Disorder (ADHD). Clin Psychol Rev. 2008;28:801-823.

Vaa T. ADHD and relative risk of accidents in road traffic: A meta-analysis. Accid Anal Prev. 2014;62:414-425.

Vingilis E, Macdonald S. Review: drugs and traffic collisions. Traffic Inj Prev.2002;3:1-11.

Vingilis E, Wilk P. The effects of health status, distress, alcohol and medicinal drug use on subsequent motor vehicle injuries. Accid Anal Prev. 2008;40:1901-1907.

Wåhlstedt C, Thorell LB, Bohlin G. Heterogeneity in ADHD: Neuropsychological pathways, comorbidity and symptom domains. J Abnorm Child Psychol. 2009;37:551-564.

Weafer J, Camarillo D, Fillmore MT, Milich R, Marczinski CA. Simulated driving performance of adults with ADHD: comparisons with alcohol intoxication. Exper Clin Psychopharmacol. 2008;16:251-263.

Weiss G, Hechtman L, Milroy T, Perlman T. Psychiatric status of hyperactives as adults: A controlled prospective 15- year follow-up of 63 hyperactive children. J Am Acad Child Psychiat. $1985 ; 24: 211-220$.

Wells-Parker E, Ceminsky J, Hallberg V, et al. An exploratory study of the relationship between road rage and crash experience in a representative sample of US drivers. Accid Anal Prev. 34, 271-278.

WHO ASSIST Working Group. Alcohol, smoking and substance involvement screening test (ASSIST): Development, reliability and feasibility. Addiction 2002;97:1183-94.

Wolraich ML, Wibbelsman CJ, Brown TE, et al. Attention-deficit/hyperactivity disorder among adolescents: A review of the diagnosis, treatment, and clinical implications. Pediatrics. 2005;115:1734-1746

Woodword L, Fergusson DM, Horwood LJ. Driving outcomes of young people with attentional difficulties in adolescence. J Am Acad Child Adolesc Psychiatry. 2000;39:627434. 
Young S, Roone B, Tyson C. Comorbidity and psychosocial profile of adults with Attention Deficit Hyperactivity Disorder. Pers Indiv Differ. 2003;35:743-755. 
Table 1 ADHD screener status by socio-demographic, previous ADHD diagnosis and medication use, comorbidities, substance use/abuse and driving variables.

\begin{tabular}{|c|c|c|c|c|c|c|}
\hline Variables & & $\mathrm{ADHD}+\mathrm{s}$ & rreen & ADHD- sc & reen & \\
\hline & & $N$ & $\%$ & $N$ & $\%$ & $P^{*}$ value \\
\hline age & $18-24$ & 21 & 20.0 & 346 & 10.8 & $.000 *$ \\
\hline & $25-44$ & 45 & 42.9 & 1133 & 35.5 & \\
\hline & $45-64$ & 36 & 34.3 & 1193 & 37.3 & \\
\hline & $\geq 65$ & 3 & 2.9 & 524 & 16.4 & \\
\hline sex & Female & 57 & 54.3 & 1650 & 50.7 & .466 \\
\hline & male & 48 & 45.7 & 1606 & 49.3 & \\
\hline ADHD & Previous dia & 11 & 10.6 & 60 & 1.8 & $.000^{*}$ \\
\hline diagnosis & never & 93 & 89.4 & 3194 & 98.2 & \\
\hline ADHD meds & Taken & 10 & 9.6 & 40 & 1.2 & $.000^{*}$ \\
\hline & Never taken & 94 & 90.4 & 3214 & 98.8 & \\
\hline Distress (GHQ) & Yes $(\geq 3)$ & 49 & 46.7 & 402 & 12.3 & $.000^{*}$ \\
\hline & No $(0-2)$ & 56 & 53.3 & 2854 & 87.7 & \\
\hline ASP screen & Yes $(\geq 3)$ & 4 & 4.1 & 7 & 0.2 & $.000^{*}$ \\
\hline & No $(0-2)$ & 94 & 95.9 & 3157 & 99.8 & \\
\hline Anti-anxiety & Taken last 12 mo & 37 & 35.6 & 218 & 6.7 & $.000^{*}$ \\
\hline meds & No & 67 & 64.4 & 3034 & 93.3 & \\
\hline Anti-depressant & Taken last 12 mo & 35 & 33.3 & 183 & 5.6 & $.000 *$ \\
\hline meds & No & 70 & 66.7 & 3067 & 94.4 & \\
\hline Anti-pain meds & Taken last 12 mo & 31 & 29.8 & 651 & 20.1 & .016 \\
\hline & No & 73 & 70.2 & 2580 & 79.9 & \\
\hline Binge drinking & Yes ( $\geq 1$ past yr) & 58 & 55.3 & 1348 & 41.7 & .006 \\
\hline & No & 47 & 44.8 & 1884 & 58.3 & \\
\hline Cannabis use & Yes (ever in lifetime) & 77 & 73.3 & 1338 & 41.2 & $.000^{*}$ \\
\hline lifetime & No (never) & 28 & 26.7 & 1907 & 58.8 & \\
\hline Cocaine use & Yes (ever in lifetime) & 23 & 21.9 & 213 & 6.5 & $.000 *$ \\
\hline lifetime & No (never) & 82 & 78.1 & 3040 & 93.5 & \\
\hline AUDIT & Yes $(\geq 8)$ & 23 & 22.3 & 419 & 13.2 & .007 \\
\hline & No $(0-7)$ & 80 & 77.7 & 2763 & 86.8 & \\
\hline ASSIST & Moderate/high $(\geq 4)$ & 13 & 12.5 & 142 & 4.4 & $.000^{*}$ \\
\hline & Low $(0-3)$ & 91 & 87.5 & 3108 & 95.6 & \\
\hline Drinking & Past yr & 3 & 2.9 & 187 & 5.7 & .208 \\
\hline driving & No & 102 & 97.1 & 3070 & 94.3 & \\
\hline Cannabis & Past yr & 4 & 3.8 & 61 & 1.9 & .160 \\
\hline driving & No & 101 & 96.2 & 3176 & 98.1 & \\
\hline Racing & Past yr & 2 & 1.9 & 28 & 0.9 & .264 \\
\hline & No & 103 & 98.1 & 3223 & 99.1 & \\
\hline Collisions & Past yr & 13 & 12.4 & 183 & 5.6 & .004 \\
\hline & No & 92 & 87.6 & 3073 & 94.4 & \\
\hline
\end{tabular}

*Significant $P$ value with Bonferroni adjustment for 18 comparisons $=.0028$ 
Table 2 Collision status by ADHD screener status, previous ADHD diagnosis and medication use, comorbidities, substance use/abuse and driving variables.

\begin{tabular}{|c|c|c|c|c|c|c|}
\hline Variables & & Collision & ast $y r$ & No collisio & n past yr & \\
\hline & & $N$ & $\%$ & $N$ & $\%$ & $P^{*}$ value \\
\hline age & $18-24$ & 34 & 16.3 & 343 & 10.7 & $.000^{*}$ \\
\hline & $25-44$ & 91 & 43.8 & 1135 & 35.3 & \\
\hline & $45-64$ & 66 & 31.7 & 1200 & 37.3 & \\
\hline & $\geq 65$ & 17 & 8.2 & 537 & 16.7 & \\
\hline sex & Female & 108 & 50.2 & 1665 & 50.7 & .884 \\
\hline & male & 107 & 49.8 & 1616 & 49.3 & \\
\hline ADHD positive & Yes $(\geq 14)$ & 13 & 6.6 & 92 & 2.9 & .004 \\
\hline screen & No (6-13) & 183 & 93.4 & 3073 & 97.1 & \\
\hline ADHD & Previous diagr & 5 & 2.3 & 67 & 2.0 & .764 \\
\hline diagnosis & never & 208 & 97.7 & 3208 & 98.0 & \\
\hline ADHD meds & Taken & 1 & 0.5 & 49 & 1.5 & .220 \\
\hline & Never taken & 212 & 99.5 & 3226 & 98.5 & \\
\hline Distress (GHQ) & Yes $(\geq 3)$ & 42 & 19.6 & 427 & 13.0 & .006 \\
\hline & No $(0-2)$ & 172 & 80.4 & 2854 & 87.0 & \\
\hline ASP screen & Yes $(\geq 3)$ & 2 & 1.0 & 9 & 0.3 & .091 \\
\hline & No $(0-2)$ & 203 & 99.0 & 3177 & 99.7 & \\
\hline Anti-anxiety & Taken last $12 \mathrm{mo}$ & 24 & 11.4 & 237 & 7.2 & 0.27 \\
\hline meds & No & 187 & 88.6 & 3038 & 92.8 & \\
\hline Anti-depressant & Taken last $12 \mathrm{mo}$ & 15 & 7.0 & 208 & 6.4 & .717 \\
\hline meds & No & 200 & 93.0 & 3066 & 93.6 & \\
\hline Anti-pain meds & Taken last $12 \mathrm{mo}$ & 56 & 26.8 & 663 & 20.3 & .026 \\
\hline & No & 153 & 73.2 & 2597 & 79.7 & \\
\hline Binge drinking & Yes ( $\geq$ 1 past yr) & 108 & 60.7 & 1344 & 51.1 & .014 \\
\hline & No & 70 & 39.3 & 1284 & 48.9 & \\
\hline Cannabis use & Yes (ever in lifetime) & 114 & 53.3 & 1329 & 40.7 & $.000^{*}$ \\
\hline lifetime & No (never) & 100 & 46.7 & 1938 & 59.3 & \\
\hline Cocaine use & Yes (ever in lifetime) & 25 & 11.6 & 217 & 6.6 & .005 \\
\hline lifetime & No (never) & 190 & 88.4 & 3060 & 93.4 & \\
\hline AUDIT & Yes $(\geq 8)$ & 28 & 13.9 & 422 & 13.2 & .754 \\
\hline & No $(0-7)$ & 173 & 86.1 & 2785 & 86.8 & \\
\hline ASSIST & Moderate/high $(\geq 4)$ & 25 & 11.6 & 137 & 4.2 & $.000^{*}$ \\
\hline & Low $(0-3)$ & 190 & 88.4 & 3137 & 95.8 & \\
\hline Drinking & Past yr & 8 & 3.7 & 184 & 5.6 & .254 \\
\hline driving & No & 206 & 96.3 & 3097 & 94.4 & \\
\hline Cannabis & Past yr & 7 & 3.3 & 60 & 1.8 & .144 \\
\hline driving & No & 208 & 96.7 & 3198 & 98.2 & \\
\hline Racing & Past yr & 9 & 4.2 & 26 & 0.8 & $.000^{*}$ \\
\hline & & 205 & 95.8 & 3245 & 99.2 & \\
\hline
\end{tabular}

*Significant $P$ value with Bonferroni adjustment for 18 comparisons $=.0028$ 
Table 3 Sequential Logistic regression for self-reported collision involvement in past 12 months

\begin{tabular}{|c|c|c|c|c|c|c|c|}
\hline & $\beta$ & S.E. & Wald & $d f$ & Sig. & $\operatorname{Exp}(\beta)$ & 95\% C.I. \\
\hline Constant & -2.794 & .080 & 1219.574 & 1 & .000 & .061 & \\
\hline \multicolumn{8}{|l|}{ Block 1} \\
\hline Age Group $18-24$ & & & 18.990 & 3 & .000 & & \\
\hline $25-44$ & .138 & .255 & .295 & 1 & .587 & 1.148 & $.697-1.893$ \\
\hline $45-64$ & -.458 & .270 & 2.883 & 1 & .090 & .633 & $.373-1.073$ \\
\hline $65+$ & -.963 & .370 & 6.769 & 1 & .009 & .382 & $.185-.789$ \\
\hline Sex (Male) & .060 & .164 & .131 & 1 & .717 & 1.061 & $.769-1.465$ \\
\hline Driving $\mathrm{km}$ in a week & .000 & .000 & 5.949 & 1 & .015 & 1.000 & $1.000-1.001$ \\
\hline Constant & -2.717 & .242 & 125.756 & 1 & .000 & .066 & \\
\hline \multicolumn{8}{|l|}{$\begin{array}{l}\text { Model } X^{2}=26.568, d f=5, P<.000 \\
-2 \text { Log likelihood }=1241.489 \\
\text { Hosmer and Lemeshow Test } \\
X^{2}=3.201, d f=8, P=.921\end{array}$} \\
\hline \multicolumn{8}{|l|}{ Block 2} \\
\hline Age Group $18-24$ & & & 18.708 & 3 & .000 & & \\
\hline $25-44$ & .142 & .255 & .309 & 1 & .578 & 1.152 & $.699-1.901$ \\
\hline $45-64$ & -.450 & .270 & 2.802 & 1 & .094 & .636 & $.375-1.080$ \\
\hline $65+$ & -.953 & .371 & 6.599 & 1 & .010 & .386 & $.186-.798$ \\
\hline Male & .059 & .164 & .129 & 1 & .720 & 1.06 & $.769-1.464$ \\
\hline Weekly Driving km & .000 & .000 & 6.026 & 1 & .014 & 1.000 & $1.000-1.001$ \\
\hline ADHD+ Status & .156 & .423 & .135 & 1 & .713 & 1.169 & $.510-2.679$ \\
\hline Constant & -2.727 & .244 & 124.771 & 1 & .000 & .065 & \\
\hline \multicolumn{8}{|l|}{$\begin{array}{l}\text { Model } X^{2}=26.699, d f=6, P<.000 \\
-2 \text { Log likelihood=1241.359 } \\
\text { Hosmer and Lemeshow Test } \\
X^{2}=2.901, d f=8, P=.940\end{array}$} \\
\hline \multicolumn{8}{|l|}{ Block 3} \\
\hline Age Group $18-24$ & & & 17.871 & 3 & .000 & & \\
\hline $25-44$ & .127 & .256 & .247 & 1 & .619 & 1.135 & $.688-1.874$ \\
\hline $45-64$ & -.455 & .271 & 2.827 & 1 & .093 & .634 & $.373-1.078$ \\
\hline $65+$ & -.944 & .371 & 6.460 & 1 & .011 & .389 & $.188-.806$ \\
\hline Male & .051 & .165 & .94 & 1 & .759 & 1.052 & $.761-1.455$ \\
\hline Weekly Driving km & .000 & .000 & 6.331 & 1 & .012 & 1.000 & $1.000-1.001$ \\
\hline ADHD+ Status & .021 & .439 & .002 & 1 & .962 & 1.021 & $.432-2.415$ \\
\hline ASPD (+) & 1.113 & .832 & 1.790 & 1 & .181 & 3.042 & $.596-15.522$ \\
\hline $\mathrm{GHQ}(3+)$ & .175 & .224 & .610 & 1 & .435 & 1.191 & $.768-1.849$ \\
\hline Constant & -2.747 & .248 & 122.940 & 1 & .000 & .064 & \\
\hline $\begin{array}{l}\text { Model } X^{2}=28.796, d f=8, P<.000 \\
-2 \text { Log likelihood=1239.262 } \\
\text { Hosmer and Lemeshow Test } \\
X^{2}=5.976, d f=8, P=.650\end{array}$ & & & & & & & \\
\hline \multicolumn{8}{|l|}{ Block 4} \\
\hline Age Group 18-24 & & & 14.099 & 3 & .003 & & \\
\hline $25-44$ & .185 & .263 & .496 & 1 & .481 & 1.203 & $.719-2.013$ \\
\hline $45-64$ & -.369 & .279 & 1.749 & 1 & .186 & .692 & $.400-1.195$ \\
\hline
\end{tabular}




\begin{tabular}{|l|r|r|r|r|r|r|r|}
\hline \multicolumn{1}{|c|}{$65+$} & -.745 & .380 & 3.838 & 1 & .050 & .475 & $.225-1.000$ \\
\hline Male & .008 & .167 & .003 & 1 & .959 & 1.009 & $.727-1.399$ \\
\hline Weekly Driving km & .000 & .000 & 5.846 & 1 & .016 & 1.000 & $1.000-1.001$ \\
\hline ADHD+ Status & -.126 & .446 & .080 & 1 & .777 & .882 & $.368-2.113$ \\
\hline ASPD (+) & 1.024 & .849 & 1.456 & 1 & .228 & 2.784 & $.528-14.690$ \\
\hline GHQ(3+) & .108 & .227 & .228 & 1 & .633 & 1.114 & $.715-1.737$ \\
\hline ASSIST & .567 & .315 & 3.248 & 1 & .071 & 1.763 & $.952-3.266$ \\
\hline Used Cannabis in Lifetime & .339 & .177 & 3.659 & 1 & .056 & 1.404 & $.992-1.988$ \\
\hline Used Cocaine in Lifetime & -.005 & .294 & .000 & 1 & .987 & .995 & $.559-1.771$ \\
\hline Constant & -2.987 & .265 & 126.622 & 1 & .000 & .050 & \\
\hline $\begin{array}{l}\text { Model } X^{2}=38.317, d f=11, P<.000 \\
-2 \text { Log likelihood }=1229.741\end{array}$ & & & & & & & \\
Hosmer and Lemeshow Test & & & & & & & \\
$X^{2}=3.296 d f=8, P=.914$ & & & & & & & \\
\hline
\end{tabular}

